\title{
Quality Safety Risk Evaluation of Agriculture Product Cold Chain:A 4M1E Analysis Framework
}

\author{
Qiao Liu, XinShen" \\ College of Economics and Management, Shanghai Ocean University, Shanghai, China \\ *corresponding Author.
}

\begin{abstract}
Due to the lack of an efficient cold chain logistics process, China's agricultural postpartum loss has been serious for a long time, and frequent food safety accidents occur. It is of necessity to establish a quality safety management system for the agricultural product cold chain in China. From the five dimensions of man, machine, material, method, and environment (4MIE), we identify the quality risk structure of the agri-food cold chain. An evaluation system is established with the combination of the analytic hierarchy process and entropy value method. A case study demonstrates the effectiveness of the risk assessment system to help enterprises for decision-making on cold chain operations.
\end{abstract}

Keywords: Agricultural products, cold chain,quality risk

\section{Introduction}

China is a vast country, agricultural products in different locations and regional resource endowment differences have an important impact on the circulation process of agricultural products. Meat, poultry, aquatic products, vegetables, fruits, eggs, and other fresh agricultural products reach the hands of consumers after a long journey including being collected from the origin (or slaughter, fishing) and going through all links of product processing, packaging, storage, transportation, distribution and retailing. For a long time, due to the lack of whole-process quality risk monitoring and management of the cold chain, the postpartum loss of agricultural products in China has been serious, and food safety accidents occur frequently. Therefore, it is particularly critical to identify and evaluate the quality risk of the cold chain for agricultural products in China.

The concept of the cold chain was first put forward by Albert Barrier and O.A.Ruddichin 1894. In the 1990s, with the development of supply chain theory, the cold chain gradually attracted attention and developed rapidly. The (perishable) cold chain is significantly different from the general supply chain, mainly reflected in the temperature sensitivity and a series of resulting differences, such as product type, product information, value retention, operating cost, traffic tolerance, the convenience of assembly, customer experience and so on. This study mainly focuses on the agri-food cold chain(ACC). Agricultural products have a particularity of products. ACC is generally recognized as a special supply chain system to ensure the quality of product quality safetyfor meat, poultry, aquatic products, vegetables, fruits, eggs, and other fresh agricultural products under the low-temperature control of the suitable environment.The quality safety risk of the ACC(ACCQR thereafter)is different from the general food supply chain risk. The ACC also has the risk of chain disruption. However, due to the diversity, seasonality, complexity, and other characteristics of agricultural products, the ACCQR has been objectively determined to run through all the nodes and processes of the supply chain "from farm to fork". In the process of value transmission of agricultural products in the supply chain, the risk problems that do not conform to the "inherent characteristics" and cannot "meet the demand" must be combined with the specific environment of the ACC and the specific category of the definition of "quality" to make a systematic analysis. This paper intends to identify its forming factors from the perspective of quality and establish a quality safety risk assessment system for the ACC, to provide positive thoughts and beneficial exploration for the quality and safety assurance of agricultural products in

ISSN: 0010-8189

(C) CONVERTER 2020

www.converter-magazine.info 
China.

\section{Literature Review and Research Framework}

\subsection{M1E framework}

$4 \mathrm{M} 1 \mathrm{E}$ is the classical theory of quality management, which refers to the five factors affecting quality, respectively from Man, Machine, Material, Method, and Environment. The so-called Man-factor refers to all personnel at the scene, including the supervisor, drivers, production staff, porters, and other people. Machine refers to the auxiliary production appliances such as equipment and tools used in quality production. Material refers to a substance used for products such as semi-finished products, accessories, and raw materials. Method refers to rules and regulations to be followed in the production process, including process instructions, standard process instructions, production drawings, production schedules, product operating standards, inspection standards, and various operating procedures, etc. Environment refers to the internal and external environment that affects the quality of the product. It is worth noting that quality management theory and risk management theory are quite intertwined. This point, from the ISO9001:2015 version of the quality management system requirements "based on risk thinking" can be seen. In the standard, risk identification and risk control become the requirements of the standard.

\subsection{M1E Analysis}

First of all, from the perspective of Man-factors (including managers, employees, and customers), Deming ${ }^{[3]}$ believed that $90 \%$ of the problems were caused by managers, and the decline began at the top. Apparao, Garnevska\&Shadbolt listed the "lack of top-level commitment of top management" as fundamental restrictive factors affecting the agricultural products quality risk. Lack of customer quality awareness may also amplify suppliers' risky behaviours ${ }^{[2]}$.

Secondly, Machine-factors are from the cold chain system-related hardware and software. Insufficient cold storage facilities lead to the frequent occurrence of food safety incidents, coupled with high installation and operation $\operatorname{costs}^{[4,5]}$, imperfect traceability system ${ }^{[6]}$, and other factors, which further affect the information transmission of the ACC and increase the probability of quality risks.

Thirdly, Material-factors are from the attribute of agricultural products themselves. This may be due to inadequate education and training of farmers at source ${ }^{[1]}$, manifested as unreasonable packaging ${ }^{[7]}$, excessive pesticide residues $^{[2,6]}$. In addition, the CLs of agricultural products in pre-cooling, processing, storage, transportation, and sales all have temperature control requirements, while the temperature control requirements of different types of agricultural products are not consistent ${ }^{[8]}$.

The fourth cause of Methods comes from the cold chain organizational factors. There are many kinds of agricultural products with loads of circulation links and scattered supply chain nodes, and ACC cannot realize integration as what does within the industrial product supply chain. There are loads of "information islands" between member enterprises and core enterprises, lack of overall cooperation ${ }^{[6]}$. The participation of middlemen is different, which leads to failure or even chain disruption due to quality risks resulting from the inconsistency of effect, efficiency, and adaptability.

Lastly, comes from the Environment or media factors. Whether ACC enterprises comply with law and government regulation often depends on the trade-off between law-abiding gains and illegal losses ${ }^{[1]}$. Government supervision has a positive impact on the quality safety control willingness of core enterprises in the ACC ${ }^{[2]}$, and then affects the quality risk of the ACC. Furthermore, the whole cold chain logistics standard is relatively inadequate in China. The agricultural product market belongs to the "lemon market", and the problem of "adverse selection" of consumers ${ }^{[9]}$ has lowered the quality expectation of the whole market. Therefore, the more opaque the market information is, the

ISSN: 0010-8189

(C) CONVERTER 2020 
higher the ACCQR tends to be.

\section{Construction ofevaluation index system for ACCQR}

\subsection{Selection of indicators}

Combined with the analysis results in the previous section, the quality safety risks of the ACC are deconstructed with one target layer, five criterion layers, and 19 indicators determined. This is shown in Table 1.

Table 1 Quality safety risk index system of ACC

\begin{tabular}{|c|l|l|}
\hline \multirow{4}{*}{ Man $\left(\mathrm{U}_{1}\right)$} & $\mathrm{U}_{11}$ & Top management lacks cold chain quality awareness \\
\cline { 2 - 3 } & $\mathrm{U}_{12}$ & Middle and senior managers lack cold chain expertise, skills and attitudes \\
\cline { 2 - 3 } & $\mathrm{U}_{13}$ & Grassroots employeeslack cold chain expertise, skills and attitudes \\
\cline { 2 - 3 } & $\mathrm{U}_{14}$ & Customers' awareness of quality risk is insufficient \\
\hline \multirow{4}{*}{ Machine $\left(\mathrm{U}_{2}\right)$} & $\mathrm{U}_{21}$ & Cold chain logistics facilities and equipment insufficient \\
\cline { 2 - 3 } & $\mathrm{U}_{22}$ & Insufficient traceability for agricultural products cold chain \\
\cline { 2 - 3 } & $\mathrm{U}_{23}$ & Insufficient cold chain process quality testing equipment \\
\cline { 2 - 3 } & $\mathrm{U}_{24}$ & Insufficient cold chain process shelf life monitoring system \\
\hline \multirow{5}{*}{ Materials $\left(\mathrm{U}_{3}\right)$} & $\mathrm{U}_{31}$ & Harvesting link farmers education and training \\
\cline { 2 - 3 } & $\mathrm{U}_{32}$ & Pesticide residues \\
\cline { 2 - 3 } & $\mathrm{U}_{33}$ & Difference of temperature control of agricultural products \\
\cline { 2 - 3 } & $\mathrm{U}_{34}$ & Insufficient Packaging of agricultural products \\
\hline \multirow{5}{*}{ Methods $\left(\mathrm{U}_{4}\right)$} & $\mathrm{U}_{41}$ & Cold chain circulation link breakdown \\
\cline { 2 - 3 } & $\mathrm{U}_{42}$ & Cold chain organization low collaboration degree \\
\cline { 2 - 3 } & $\mathrm{U}_{43}$ & Luck of Enterprise cold chain operation specifications and operating standards \\
\cline { 2 - 3 } & $\mathrm{U}_{44}$ & Luck of Temperature recording of key links in cold chain business \\
\cline { 2 - 3 } & $\mathrm{U}_{45}$ & Failed to pass the quality system certification \\
\hline \multirow{5}{*}{ Environment $\left(\mathrm{U}_{5}\right)$} & $\mathrm{U}_{51}$ & Government regulation. \\
\cline { 2 - 3 } & $\mathrm{U}_{52}$ & Peer competition pressure. \\
\cline { 2 - 3 } & $\mathrm{U}_{53}$ & Cold chain professional standardization and industry specifications. \\
\cline { 2 - 3 } & $\mathrm{U}_{54}$ & Market information asymmetry degree \\
\cline { 2 - 3 } & $\mathrm{U}_{55}$ & The degree of public quality indifference \\
\hline
\end{tabular}

In the table, Man-factor is mainly investigated from three different levels of actors in agricultural cold chain enterprises, namely the top management, middle and senior management, and grass-roots employees. These indicators belong to subjective qualitative indicators. The risks are mainly considered by whether the cold chain logistics facilities cover the whole cold chain, whether there is a cold chain traceability system for agricultural products, and quality testing equipment for the cold chain process.

The Machine-factor is mainly based on the attributes of the cold chain agricultural products evaluated, including four indicators such as the training rate of farmers in the harvest link, pesticide residues, differences in temperature control of agricultural products, and packaging of agricultural products. The reason why farmers' training is included in the factor risk is that educated and trained farmers will pay attention to low-temperature operation in the harvest process of planting and breeding to reduce the risk of product deterioration, and the specific implementation can be obtained through stratified sampling survey samples. Pesticide residues seem to have nothing to do with the operation of the cold chain, but according to the understanding of the value chain, each link of the cold chain should ensure the value increase or keep the value unchanged in the process of transferring agricultural products, and should not make its value depreciate. Pesticide, as the product of the contradiction between crop growth quality and growth efficiency, has been widely important. It can be measured by the detection rate of pesticide residues and other indicators. The difference in temperature control of agricultural products refers to whether materials with large differences in temperature control requirements are transported together. Products with different temperature control requirements should be placed in different temperature controls. Improper packaging of agricultural products is also a material factor that causes quality and safety risks. The possibility of

ISSN: 0010-8189

(C) CONVERTER 2020

www.converter-magazine.info 
potential risks can be determined through inspection of packaging.

Method-factor mainly comes from the organization methods of the ACC, such as the number of circulation nodes of the cold chain, the degree of organization and cooperation of the cold chain, the soundness of the enterprise's cold chain operation norms and operating standards, the temperature record of the key links of the whole cold chain business and the quality system certification, etc. The higher the proportion of low-temperature treatment applied in the whole link, the lower the risk; otherwise, the higher the risk.

Environmental risks mainly come from stakeholders, such as the degree of government regulation, peer competition pressure, the degree of cold-chain standardization and industry norms, as well as the degree of market information transparency. In the evaluation of the degree of government regulation, the evaluation-maker will conduct subjective evaluation according to the government's regulation intensity on the quality and safety of different varieties of agricultural products. The pressure of peer competition will also force enterprises to pay attention to product quality and safety, which can be measured by the degree of industry concentration. The higher the degree of industry concentration, the smaller the risk, and vice versa. Cold chain professional standardization and its industry norms reflect the basic state of the industry, mainly examining the close degree of enterprises and industry associations. The degree of market information asymmetry also has an impact on the ACCQR. The more asymmetric the information is, the greater the risk will be. The more the public ignores quality, the greater the risk will be.

\subsection{Determination of weights}

The analytic hierarchy process is used to determine the subjective weight, the entropy method is used to determine the objective weight, and the multiplication method is used to combine the weight of each evaluation index.

(1) Construct the horizontal matrix $\mathrm{X}$ of the index layer evaluation, whose elements are the evaluated objects

$$
\begin{gathered}
C_{i j}^{s}(\mathrm{i}=1,2 \ldots \mathrm{M} ; \mathrm{j}=1,2 \ldots, \mathrm{n}) \text { of indicator } S \\
U_{i j}(s=1,2, \ldots, q)
\end{gathered}
$$

(2) The horizontal matrix $\mathrm{X}$ is normalized, and its elements are set as $X_{i j}^{s}$

(3) Calculate the entropy of the indicator $U_{i j}$. The decision information of each evaluation indicator can be expressed by its entropy value $e_{i j}$

$$
e_{i j}=-\lambda \sum_{s=1}^{q} x_{i j}^{s} \ln x_{i j}^{s},
$$

$$
\lambda=1 / \ln q
$$

(4) The coefficient of difference for $U_{i j}$ was calculated. For indicators, the greater the difference of indicators, the greater the effect on scheme evaluation, the smaller the entropy value, and the larger the weight coefficient of indicators. On the contrary, the smaller the difference is, the smaller the effect on scheme evaluation will be, and the smaller the weight coefficient of indicators will be.The calculation formula of difference coefficient is as follows:

ISSN: 0010-8189 


$$
d_{i j}=1-e_{i j}(2)
$$

The weight vector of the index obtained by entropy value method

$$
\boldsymbol{\beta}_{i}=\left(\begin{array}{llllll}
\beta_{i 1} & \beta_{i 2} & \mathbf{L} & \beta_{i j} & \mathbf{L} & \beta_{i n}
\end{array}\right)_{(3)}
$$

$$
\beta_{i j}=\frac{d_{i j}}{\sum_{j=1}^{n} d_{i j}}
$$

In order to magnify the importance difference between the indicators, the composite method of multiplication is often used to give weight to the evaluation indicators, that is, the weight coefficients determined by the subjective and objective weighting methods are first multiplied, and then the product is normalized to obtain the combined weight of the indicators $U_{i j}$ in the index layer:

$$
\begin{gathered}
\boldsymbol{w}_{i}=\left(\begin{array}{llllll}
w_{i 1} & w_{i 2} & \mathrm{~L} & w_{i j} & \mathrm{~L} & w_{i n}
\end{array}\right), \\
w_{i j}=\frac{a_{i j} \times \beta_{i j}}{\sum_{j=1}^{n} a_{i j} \times \beta_{i j}}
\end{gathered}
$$

Similarly, the index weight vector of the standard layer can be obtained as:

$$
\boldsymbol{W}=\left(\begin{array}{llllll}
w_{1} & w_{2} & \mathrm{~L} & w_{i} & \mathrm{~L} & w_{m}
\end{array}\right)_{(5)}
$$

\subsection{Evaluation model}

The evaluation indexes are divided into five standards according to their merits and demerits. The scores are 5, 4, 3, 2 and 1 respectively. The index grades are between two adjacent grades, and the corresponding scores are 4.5, 3.5, 2.5 and 1.5. Organize evaluation experts of $P$, whose serial number as $k=1,2 \ldots, p$. Then scores of the ACCQRwere respectively given according to the scoring criteria, so as to obtain the evaluation sample matrix:

$$
\begin{gathered}
\boldsymbol{D}_{s}=\left(\begin{array}{ccccccc}
d_{11}^{1} & d_{11}^{2} & \mathrm{~L} & d_{11}^{k} & \mathrm{~L} & d_{11}^{p} \\
d_{12}^{1} & d_{12}^{2} & \mathrm{~L} & d_{12}^{k} & \mathrm{~L} & d_{12}^{p} \\
\mathrm{M} & \mathrm{M} & \mathrm{O} & \mathrm{M} & \mathrm{O} & \mathrm{M} \\
d_{i j}^{1} & d_{i j}^{2} & \mathrm{~L} & d_{i j}^{k} & \mathrm{~L} & d_{i j}^{p} \\
\mathrm{M} & \mathrm{M} & \mathrm{O} & \mathrm{M} & \mathrm{O} & \mathrm{M} \\
d_{m n}^{1} & d_{m n}^{2} & \mathrm{~L} & d_{m n}^{k} & \mathrm{~L} & d_{m n}^{p}
\end{array}\right)(6) \\
d_{i j}^{k} \quad(i=1,2, \cdots, m ; j=1,2, \cdots, n ; k=1,2, \cdots, p)
\end{gathered}
$$

This paper uses the grey system to evaluate the grey categories is to determine the number of grey grades, grey number, and whitening weight function. According to the scoring level of the above indexes, five grey categories are used for the ACCQR. The grey category number is $\mathrm{e}(\mathrm{e}=1,2,3,4,5)$, which respectively represent five standards, such as very $\operatorname{good}(e=1), \operatorname{good}(e=2)$, average $(e=3), \operatorname{poor}(e=4)$, and very poor $(e=5)$. The corresponding grey grade $\otimes_{1} \in[5, \infty] \otimes_{2} \in[0,4,8] \otimes_{3} \in[0,3,6] \otimes_{4} \in[0,2,4] \otimes_{5} \in[0,1,2]$, all five whitening weight functions from 
$f_{1}$ (Grey glass 1)to $f_{5}$ (Grey glass 5 ) follow the formula of Alfaro-Saiz, et al ${ }^{[10]}$.

For the evaluation index $u_{i j}$ belonging to the evaluation grey category $e$, the evaluation coefficient is denoted as $x_{i j}^{e}$

$$
x_{i j}=\sum_{e=1}^{5} x_{i j}^{e}(7)
$$

The grey evaluation weight matrix $R_{i}$ of all the indicators $U_{i j}$ belonging to the cold chain $U_{i}$ is obtained after calculating the grey evaluation weight vector of all the indicators belonging to ACCQR for each evaluation grey category,

$$
\boldsymbol{R}_{i}=\left(\begin{array}{c}
\boldsymbol{r}_{i 1} \\
\boldsymbol{r}_{i 2} \\
\mathrm{M} \\
\boldsymbol{r}_{i j}
\end{array}\right)=\left(\begin{array}{ccccc}
r_{i 1}^{1} & r_{i 1}^{2} & r_{i 1}^{3} & r_{i 1}^{4} & r_{i 1}^{5} \\
r_{i 2}^{1} & r_{i 2}^{2} & r_{i 2}^{3} & r_{i 2}^{4} & r_{i 2}^{5} \\
\mathrm{M} & \mathrm{M} & \mathrm{M} & \mathrm{M} & \mathrm{M} \\
r_{i j}^{1} & r_{i j}^{2} & r_{i j}^{3} & r_{i j}^{4} & r_{i j}^{5}
\end{array}\right)(8)
$$

Comprehensive evaluation of the index results are as follows:

$$
\boldsymbol{B}_{i}=\boldsymbol{w}_{i} \cdot \boldsymbol{R}_{i}=\left(\begin{array}{lllll}
b_{i 1} & b_{i 2} & b_{i 3} & b_{i 4} & b_{i 5}
\end{array}\right)(9)
$$

According to the comprehensive evaluation result $B_{i}$ of $U_{i}$, the grey evaluation weight matrix B of $U_{i}$ for the cold chain for each evaluation grey category can be calculated. Therefore, the ACCQR score U is comprehensively evaluated as the result of the comprehensive evaluation $\mathrm{Z}$. Since $\mathrm{Z}$ is a vector used to represent the gray classification degree of the comprehensive value of ACCQR, it cannot be directly used to rank the effectiveness of the evaluation objects. Therefore, it needs to be further processed to make it single valued as $\mathrm{M}$.

$$
\boldsymbol{B}=\left(\begin{array}{c}
\boldsymbol{B}_{1} \\
\boldsymbol{B}_{2} \\
\mathrm{M} \\
\boldsymbol{B}_{5}
\end{array}\right)=\left(\begin{array}{ccccc}
b_{11} & b_{12} & b_{13} & b_{14} & b_{15} \\
b_{21} & b_{22} & b_{23} & b_{24} & b_{25} \\
\mathrm{M} & \mathrm{M} & \mathrm{M} & \mathrm{M} & \mathrm{M} \\
b_{51} & b_{52} & b_{53} & b_{54} & b_{55}
\end{array}\right)
$$

$$
\boldsymbol{Z}=\boldsymbol{W} \cdot \boldsymbol{B}
$$

$$
M=\boldsymbol{Z} \cdot \boldsymbol{C}^{\mathrm{T}}, \boldsymbol{C}=\left(\begin{array}{lllll}
5 & 4 & 3 & 2 & 1
\end{array}\right)
$$

\section{Case Study}

\subsection{Case description}

Now, a supermarket needs to evaluate the ACCQR of six different core enterprises of the same variety (P1, P2, P3, P4, P5, P6), to determine which core enterprise to establish a long-term strategic supplier relationship with. The comprehensive data of the six core enterprises were collected through the market survey and field investigation. Nine experts were invited to make the score for the six ACC according to a rating list. So we get six sample 
judgment matrices D1 to D6. To avoid redundancy, only the evaluation process of the first ACCQR is listed in this paper, and other comprehensive evaluation values are obtained in the same way.

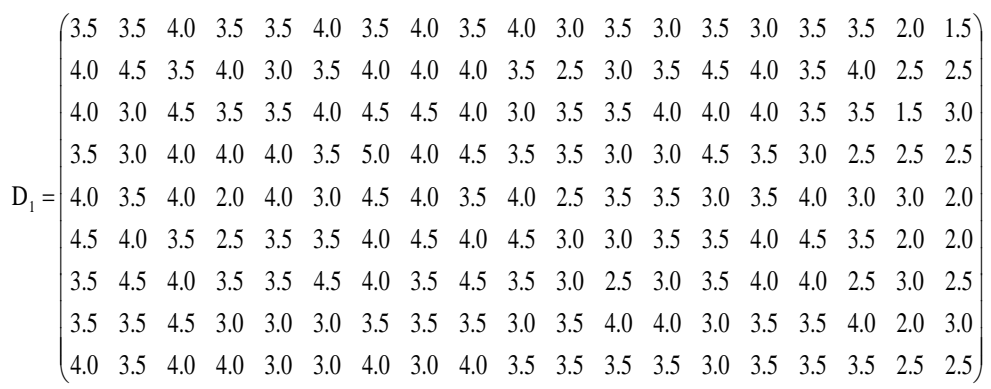

\subsection{Result}

The subjective and objective weights of each index can be obtained respectively. The final weight of the index layer can be obtained by using the combination weighting formula

$$
\boldsymbol{W}=\left(\begin{array}{lllll}
0.243 & 0.205 & 0.229 & 0.215 & 0.108
\end{array}\right)
$$

Next, the grey evaluation coefficient is calculated.For the evaluation index $u_{11}$ (service punctuality rate for example), the evaluation coefficient $x_{11}^{e}$ of the evaluation grey category $e$ (when $e=1$ )is calculated as follows:

$$
x_{11}^{1}=\sum_{k=1}^{5} f_{1}\left(d_{11}^{k}\right)=f_{1}(3.5)+f_{1}(4.0)+\cdots+f_{1}(4.0)=6.9
$$

For the evaluation index $U_{11}$, the total gray evaluation number belonging to each evaluation gray category is

$$
x_{11}=\sum_{e=1}^{5} x_{11}^{e}=x_{11}^{1}+x_{11}^{2}+x_{11}^{3}+x_{11}^{4}+x_{11}^{5}=22.775
$$

Then, the weight vector and weight matrix of grey evaluation are calculated.

$$
\begin{gathered}
\boldsymbol{r}_{11}=\left(\begin{array}{lllll}
r_{11}^{1} & r_{11}^{2} & r_{11}^{3} & r_{11}^{4} & r_{11}^{5}
\end{array}\right)=\left(\begin{array}{lllll}
0.303 & 0.368 & 0.285 & 0.044 & 0
\end{array}\right) \\
r_{11}^{e}=\frac{x_{11}^{e}}{x_{11}}
\end{gathered}
$$

Similarly, the grey evaluation vectors of other indexes can be calculated. Risk of Man-factor $\left(\mathrm{U}_{1}\right)$ devotes as $\mathrm{R}_{1}$, and others are omitted.

$$
\mathrm{R}_{1}=\left(\begin{array}{lllll}
0.303 & 0.368 & 0.285 & 0.044 & 0 \\
0.283 & 0.332 & 0.300 & 0.085 & 0 \\
0.332 & 0.381 & 0.264 & 0.023 & 0
\end{array}\right)
$$




$$
\begin{gathered}
\mathrm{B}_{1}=\mathrm{w}_{1} \cdot \mathrm{R}_{1}=\left(\begin{array}{lllll}
0.307 & 0.364 & 0.282 & 0.047 & 0
\end{array}\right) \\
\mathrm{B}^{1}=\left(\begin{array}{l}
\mathrm{B}_{1} \\
\mathrm{~B}_{2} \\
\mathrm{~B}_{3} \\
\mathrm{~B}_{4} \\
\mathrm{~B}_{5}
\end{array}\right)=\left(\begin{array}{lllll}
0.307 & 0.364 & 0.282 & 0.047 & 0 \\
0.243 & 0.298 & 0.316 & 0.143 & 0 \\
0.268 & 0.321 & 0.311 & 0.100 & 0 \\
0.284 & 0.332 & 0.278 & 0.104 & 0 \\
0.230 & 0.285 & 0.308 & 0.176 & 0
\end{array}\right)
\end{gathered}
$$

Thus, comprehensive evaluation results of ACCQR for P1 is as follows:

$$
\begin{aligned}
\mathrm{Z}_{1}=\mathrm{W} \cdot \mathrm{B}^{1}=\left(\begin{array}{lllll}
0.243 & 0.205 & 0.229 & 0.215 & 0.108
\end{array}\right)\left(\begin{array}{llllll}
0.307 & 0.364 & 0.282 & 0.047 & 0 \\
0.243 & 0.298 & 0.316 & 0.143 & 0 \\
0.268 & 0.321 & 0.311 & 0.100 & 0 \\
0.284 & 0.332 & 0.278 & 0.104 & 0 \\
0.230 & 0.285 & 0.308 & 0.176 & 0
\end{array}\right) \\
=\left(\begin{array}{llllll}
0.272 & 0.325 & 0.298 & 0.105 & 0
\end{array}\right) \\
\mathrm{M}_{1}=\mathrm{Z}_{1} \times \mathrm{C}^{\mathrm{T}}=\left(\begin{array}{llllll}
0.272 & 0.325 & 0.298 & 0.105 & 0.1
\end{array}\right)\left(\begin{array}{lllll}
5 & 4 & 3 & 2 & 1
\end{array}\right)^{\mathrm{T}}=3.764
\end{aligned}
$$

Similarly, the comprehensive evaluation values of ACCQR for P2, P3,P4,P5,P6 can be obtained as follows: $\mathrm{M}_{2}=4.136, \mathrm{M}_{3}=3.835, \mathrm{M}_{4}=3.531, \mathrm{M}_{5}=3.473, \mathrm{M}_{6}=3.936$

By comparing the value of $\mathrm{M}$, the order of ACCQRfor candidates can be obtained as follows:

$$
M_{2}>M_{6}>M_{3}>M_{1}>M_{4}>M_{5}
$$

\section{Discussion and Conclusion}

Unlike those studies of emphasis on the supply chain perspective ${ }^{[2,5]}$ with many overlapping concepts as supply chain operation risks and system risks, they aim to reduce the possibility of a different supply chain actual revenue and expected returns between because of all impacts from various uncertain factors ${ }^{[1]}$, to reduce the risk of agricultural products quality, but how to define the actual and expected revenue lay an open and much difficult question. This study hopes to base its origin and destination on "quality" rather than "system", to make a useful exploration for the research of risk management from the perspective of return to quality.

Based on the perspective of $4 \mathrm{M} 1 \mathrm{E}$, this study established the quality safety risk assessment index system of agricultural products cold-chain and selected the quality safety risk indicators from five dimensions of man, machine, material, method, and environmental factors. Analytic Hierarchy Process (AHP) and entropy method were used to quantify the subjective and objective indexes, and the risk assessment of cold chain quality safety of agricultural products was carried out through the Grey theory. The effectiveness of the risk assessment system was demonstrated through a case study. It should be noted that this ranking is not the final result of the choice of strategic partners, but only a ranking based on ACCQR. The enterprise still must consider the quality, price, delivery time and other factors to determine. This part of the process will not be analyzed in this paper. In this study, we aim to establish a new framework to look into ACCQR with classic quality perspective, andwe would like to cast brick and attract a jade for this field.

ISSN: 0010-8189

(C) CONVERTER 2020 


\section{Acknowledgements}

This paper was supported by the SHOU Research Foundation(A2-2006-20-200414/A2-2006-20-200321),China.

\section{References}

[1] R. Joshi, D.K.Banwet, R. Shankar, "Indian cold chain: modeling the inhibitors. British," Food Journal, vol. 111, no. 11, pp. 245-268, 2009.

[2] Krajcsak, Zoltan, "Successes of quality management systems through self-evaluation and commitment in different organizational cultures: A case study.” Management Decision, vol. 56, no. 7, pp. 1467-1484, 2018.

[3] D.E. Deming, "Out of the crisis: quality, productivity and competitiveposition," GeneralInformation, vol. 38, no. 7, pp. 38-49, 1986.

[4] D. Apparao,E. Garnevska, N. Shadbolt, "Examining commitment, heterogeneity and social capital within the membership base of agricultural co-operatives - A conceptual framework," Journal of Cooperative Organization and Management, vol. 7, no. 1, pp. 42-50, 2019.

[5] Z. Hao, B. Qiu, "A new risk assessment model for agricultural products cold chain logistics," Industrial management \& data systems, vol. 117, no. 9, pp. 1800-1816, 2017.

[6] B. Jja, A. Sm, C. Srb, "Social sustainability in agriculture-A system-based framework," Journal of Rural Studies, vol. 65, pp. 32-42, 2019.

[7] V. Salin, R.M. Nayga,“A cold chain network for food exports to developing countries,” International Journal of Physical Distribution \& Logistics Management, vol. 33, no. 10, pp. 918-933, 2003.

[8] A. Islam, "Dynamics and Determinants of Participation in Integrated Aquaculture - Agriculture Value Chain: Evidence from a Panel Data Analysis of Indigenous Smallholders in Bangladesh," Journal of Development Studies, vol. 6, pp. 1-22, 2021.

[9] E. Ozcan-Tok, M.U. Ozmen, E. Tok, et al., "The impact of collective action and market prices: Evidence from an online agricultural discussion forum," Online Information Review, vol. 43, no. 4, pp. 565-583, 2019.

[10] J.J. Alfaro-Saiz, M. Cerda, V. Giner-Bosch, et al., "An Evaluation of the Environmental Factors for Supply Chain Strategy Decisions Using Grey Systems and Composite Indicators," Applied Mathematical Modelling, vol. 79, pp. 490-505, 2020. 